\title{
Erratum to: Enhancing Hydrologic Modelling in the Coupled Weather Research and Forecasting-Urban Modelling System
}

\author{
Jiachuan Yang ${ }^{1} \cdot$ Zhi-Hua Wang $^{1} \cdot$ Fei Chen $^{2} \cdot$ Shiguang Miao $^{3} \cdot$ \\ Mukul Tewari ${ }^{2}$ - James A. Voogt ${ }^{4}$. Soe Myint ${ }^{5}$
}

Published online: 27 March 2015

(C) Springer Science+Business Media Dordrecht 2015

\section{Erratum to: Boundary-Layer Meteorol (2015) 155:87-109 DOI 10.1007/s10546-014-9991-6}

In the original publication of the article, the Project funding agency was not included.

The Project funding agency is given in this erratum-field measurement of the eddycovariance tower at Maryvale, West Phoenix sponsored by NSF under grant EF-1049251 is acknowledged.

The online version of the original article can be found under doi:10.1007/s10546-014-9991-6.

\section{Zhi-Hua Wang}

zhwang@asu.edu

1 School of Sustainable Engineering and the Built Environment, Arizona State University, Tempe, AZ 85287, USA

2 National Center for Atmospheric Research, Boulder, CO 80307, USA

3 Institute of Urban Meteorology, China Meteorological Administration, Beijing 100089, China

4 Department of Geography, University of Western Ontario, London, ON N6A 5C2, Canada

5 School of Geographical Sciences and Urban Planning, Arizona State University, Tempe, AZ 85287, USA 